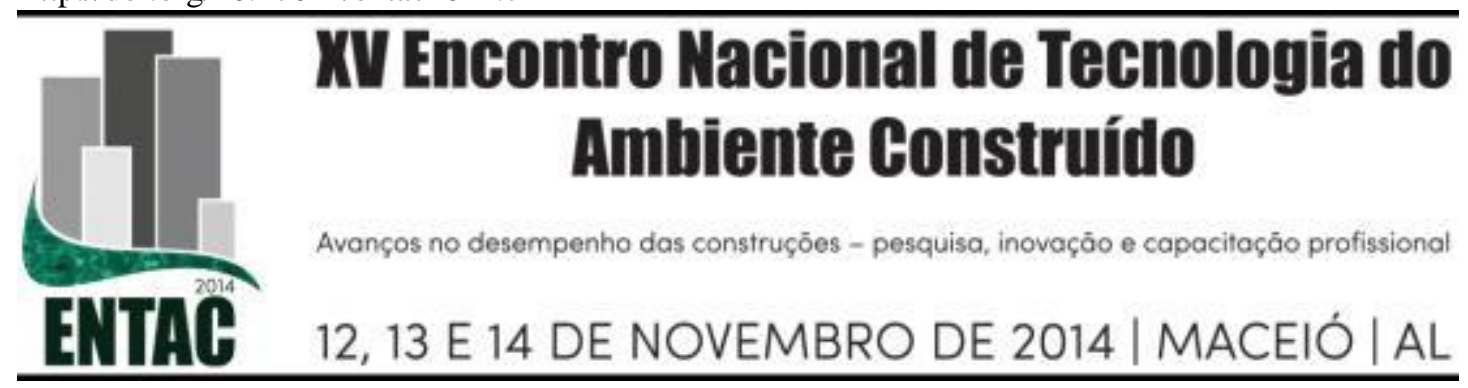

\title{
APLICAÇÃO DE ESTRATÉGIAS BIOCLIMÁTICAS EM UMA BIBLIOTECA PARQUE EM FLORIANÓPOLIS - SC
}

RIBEIRO, Natalia Fernandes (1); CARLO, Joyce Correna (2)

(1) Universidade Federal de Viçosa, e-mail: natalia.ribeiro.ufv@gmail.com, (2) Universidade Federal de Viçosa, e-mail: correnacarlo@gmail.com

\begin{abstract}
RESUMO
Segundo o Manifesto da UNESCO, de 1994, bibliotecas se configuram como o portal de acesso ao conhecimento e à informação de todos os gêneros. O objetivo deste trabalho é apresentar o processo projetual de uma Biblioteca Parque na região central de Florianópolis - SC, pertencente à Zona Bioclimática 3, que associa condições higrotérmicas específicas para o armazenamento do acervo às condições de conforto térmico e luminoso para os usuários. Os resultados obtidos são finais e a proposta foi selecionada para a exposição itinerante da VIII Bienal de Arquitetura Bioclimática José Miguel Aroztegui, em 2013. A proposta baseia-se na transferência da Biblioteca Pública de Santa Catarina para uma nova sede, localizada em uma importante área da região central da cidade. Contém um espaço público de lazer, que integra os ambientes internos de leitura aos ambientes externos pertencentes a um parque público. Desde a concepção inicial foram consideradas às condições climáticas locais e a interferência do entorno. Foi proposta a edificação principal, setorizada em três volumes: "Acervo", "Leitura" e "Apoio", para que as estratégias bioclimáticas se apresentassem coerentes com as necessidades específicas de cada espaço. Apresentou como objetivos proporcionar o condicionamento passivo e a iluminação natural difusa. Para atingir o primeiro objetivo, dutos visíveis nas fachadas e intercalados por proteções solares móveis foram projetados. Buscou-se integrar esse sistema a outras estratégias de ventilação por diferença de pressão, as quais proporcionam uma variação de opções de ventilação cruzada. Para a iluminação foi desenvolvida uma malha zenital em estrutura suspensa como cobertura, que permite a entrada da luz difusa no ambiente. A proposta final resultou em nível A pelo método prescritivo do RTQ-C, e proporcionou a concepção de espaços que fornecem maior integração com o entorno e contribuem para o processo de requalificação urbana da área.
\end{abstract}

Palavras-chave: Biblioteca Parque, Ventilação cruzada, Iluminação natural.

\begin{abstract}
According to UNESCO Public Library Manifesto (1994), libraries are configured as the gateway to knowledge and information of all genres. The objective of this paper is to present the design process of Library Park in downtown Florianópolis - SC, Brazil, belonging to the Brazilian Bioclimatic Zone 3, which associates specific hygrothermal conditions for storage of the collection and conditions for thermal and lighting comfort for users. The results are final and the proposal was selected for the exhibition of the VIII Biennial of Bioclimatic Architecture José Miguel Aroztegui (2013). The proposal is based on the transfer of the Public Library of Santa Catarina for a new headquarters, located in an important area of downtown Florianópolis - SC. Presents a public leisure space that integrates the indoors reading and outdoors belonging to a public park. From initial design were considered to local climatic conditions and the interference of surrounding area. The main building was sectored into three volumes: "Collection", "Reading room" and "Holder". The bioclimatic strategies are presented consistent with the specific needs of each space. Introduced as objective to provide passive conditioning and diffuse natural lighting. To achieve the first objective were designed, visible ducts on the facades that are interspersed with movable shading devices. Sought to integrate this system with other ventilation strategies by pressure difference, which provide a range of options for cross ventilation. For zenith lighting has been developed a mesh suspended structure as roof, allowing the entry of stray light in the room. The final proposal
\end{abstract}


resulted in the level A by the prescriptive method of $R T Q-C$, and it provided the conception of spaces that supply greater integration with the surrounding area and contribute to the process of area urban renewal.

Keywords: Library Park, Cross ventilation, Daylighting.

\section{INTRODUÇÃO}

Segundo o Manifesto da UNESCO sobre Bibliotecas Públicas (IFLA, 1994), esses espaços se configuram como o portal de acesso local ao conhecimento e à informação de todos os gêneros. A função social de uma biblioteca pública é estimular os usuários ao crescimento pessoal através do acesso à informação (ANTUNES, CAVALCANTI E ANTUNES, 2000).

A partir da análise dos novos conceitos estruturadores das bibliotecas contemporâneas, podemos destacar aquele que define as Bibliotecas Parque. Elas são centros urbanísticos formados por uma ou mais edificações e por espaços verdes circundantes de uso público. A edificação central abriga uma biblioteca e os espaços verdes são formados por um parque (CIDEU, 2012). O conceito surgiu na Colômbia, na década de 2000, para caracterizar centros culturais criados na cidade de Medellín, com o objetivo de fomentar o desenvolvimento social. O principal objetivo da aplicação desse conceito é intervir na estrutura da cidade por meio da educação, cultura e pela inclusão social das classes marginalizadas e mais vulneráveis da sociedade.

O presente artigo visa apresentar o processo de elaboração do projeto baseado em desempenho de uma Biblioteca Parque na região central de Florianópolis - SC, a fim de que a atual sede da Biblioteca Pública de Santa Catarina seja transferida. A edificação a qual abriga a atual sede, desde 1979, apresenta limitações em relação ao espaço físico, para comportar o aumento crescente do acervo e do número de usuários. Além disso, não atende ao programa de necessidades que permeia os projetos atuais para a tipologia, tal como espaços multimídia.

O conceito de Biblioteca Parque, no caso proposto para Florianópolis, é composto por um espaço público de educação e lazer que integra os ambientes internos de leitura aos ambientes externos, pertencentes ao futuro Parque Metropolitano Dias Velho, projeto do paisagista Burle Marx (1978) para o Aterro da Baía Sul. A proposta indica a associação das condições higrotérmicas específicas para o armazenamento do acervo às condições de conforto térmico e luminoso para os usuários. O projeto foi apresentado como trabalho de conclusão de curso de uma das autoras, tendo sido selecionado para a exposição itinerante da VIII Bienal de Arquitetura Bioclimática José Miguel Aroztegui, em 2013.

\section{REVISÃO BIBLIOGRÁFICA}

A cidade de Florianópolis está inserida na Zona Bioclimática 3 (ABNT, 2005). O território, com $675,409 \mathrm{~km}^{2}$, é composto pela Ilha de Santa Catarina, em 97,23\% de sua área, e o restante no continente fronteiriço (IBGE, 2010).

A temperatura média anual é de $20,3^{\circ} \mathrm{C}$, sendo que o mês de fevereiro é o mais quente, com média de $24,3^{\circ} \mathrm{C}$, e o mês de julho o mais frio, com média de $16,5^{\circ} \mathrm{C}$. A maior frequência das temperaturas está incluída entre $18^{\circ} \mathrm{C}$ e $24^{\circ} \mathrm{C}$ (GOULART, 1993).

A média anual da umidade relativa do ar é de $82 \%$, com a média mensal mínima de $82 \%$ e $81 \%$ nos meses de novembro e dezembro e máxima de $84 \%$, nos meses de junho 
e julho (GOULART, 1993). Pode-se observar que a umidade relativa é alta e uniforme durante todo o ano.

Segundo Goulart (1993), os ventos mais frequentes na cidade são o Norte e Nordeste, porém, o vento Sul apresenta maior influência em mudanças bruscas de temperatura. A frequência de ocorrência dos ventos no inverno é predominante na direção Norte e a segunda frequência é direção Sudoeste. No verão, a direção predominante é a Nordeste, seguida pela direção Norte. A distribuição dos ventos, de acordo com a direção, indica que as direções Norte e Nordeste apresentam as maiores velocidades do vento durante as quatro estações do ano.

A análise da Carta Bioclimática de Florianópolis - SC mostra que em 79,2\% das horas do ano os usuários de uma edificação que não aplica estratégias de projeto estarão em desconforto. A principal estratégia indicada para o desconforto por calor é a ventilação natural (36,4\% das horas do ano), e para o desconforto por frio é a massa térmica para aquecimento com aquecimento solar (35,4\% das horas do ano) (GOULART, 1993).

Em locais com estações quentes e frias, como Florianópolis, é necessário adotar estratégias de ventilação que proporcionem sensação de conforto na primeira, enquanto tem função higiênica e de renovação de ar na segunda, devendo-se evitar as perdas de calor no interior da edificação.

A área escolhida para a implantação da Biblioteca corresponde ao Aterro da Baía Sul, localizado na região central da Ilha de Santa Catarina. Em 1952, foi realizado o Plano Diretor da cidade, que sugeria a implantação de um aterro para atender às novas necessidades de circulação e transporte e para criar um espaço de ampliação desta região. A construção do Aterro da Baía Sul, com 630 mil m², entre os anos de 1972-74, permitiu o aumento previsto e alocou a cabeceira da uma nova ponte para a ligação entre Ilha e continente. Provocou também a expansão da área central, já sobrecarregada, com a intenção de construção de edifícios e áreas de lazer destinadas à população (MARTINS, 2012).

Em 1978 foi realizado pelo escritório do arquiteto Burle Marx o projeto de paisagismo do Aterro, para que este se transformasse no Parque Metropolitano Francisco Dias Velho (SANTOS, 1997). Tal projeto contava com quadras poliesportivas, canchas polivalentes, espelhos d'água, passarelas de conexão, áreas de estacionamento, praças, entre outros espaços de recreação, além da previsão do plantio de mais de 2.000 árvores. Do que estava previsto no projeto original, portanto, apenas uma das três passarelas, o Terminal Rita Maria (rodoviária) e o heliponto foram construídos, além do plantio das palmeiras imperiais. O espaço, por sua vez, foi ocupado da maneira conveniente a cada governo seguinte à elaboração do projeto, por instalações sem planejamento que concentra um apanhado de serviços desconexos, ainda existentes nos dias atuais.

Para o projeto de edificações que abrigam bibliotecas devem ser observadas e garantidas às condições higrotérmicas específicas para o armazenamento do acervo a fim de evitar a deterioração dos volumes, além da necessidade de garantir o conforto térmico e luminoso dos usuários (VALADÃO, 2011). Altos índices de umidade relativa são responsáveis pela promoção de reações químicas, que, combinados às altas temperaturas, podem ser catalisadores da proliferação do mofo e da atividade de insetos no material bibliotecário. A manutenção de condições estáveis é de extrema importância. Portanto, a preservação dos acervos das bibliotecas requer o controle da umidade relativa do ar e da temperatura nos ambientes internos, cujo nível de $60 \%$ pode ser considerado o limiar do dano (TRINKLEY, 2001). Os níveis devem se manter frequentes durante todo o dia, em todos os dias do ano, e os sistemas de 
condicionamento de ar não devem ser interrompidos ou desligados no período em que os espaços não estiverem em uso (OGDEN, 2001).

A preocupação com os níveis de iluminação também é de grande importância para a preservação dos materiais que constituem o acervo de uma biblioteca (OGDEN, 2001), pois, embora a luz natural nos ambientes proporcione conforto psicológico aos usuários, ela é nociva ao acervo (TRINKLEY, 2001). O maior desafio nas edificações que armazenam acervos e coleções é desenvolver maneiras de utilizar as qualidades da luz natural e, ao mesmo tempo, evitar a exposição direta.

\section{OBJETIVOS}

O objetivo deste trabalho é apresentar as soluções bioclimáticas que nortearam as decisões projetuais para a concepção da Biblioteca Parque de Santa Catarina, na região central de Florianópolis - SC. Buscou-se a associação das condições higrotérmicas específicas para o armazenamento do acervo às condições de conforto térmico e luminoso para os usuários. A intenção é relatar as escolhas que definiram a concepção dos espaços desde a fase inicial de projeto, a fim que fossem aplicadas estratégias bioclimáticas indicadas para a cidade e fossem atendidas as exigências para ambientes de armazenamento de acervo.

\section{MÉTODO}

O método desenvolvido para a realização deste trabalho foi dividido em duas etapas principais: estudos teóricos e elaboração do projeto arquitetônico. Os estudos teóricos foram baseados em uma pesquisa qualitativa de caráter exploratório (BABBIE, 1986). Estes foram divididos entre a análise bibliográfica, com ênfase em bibliotecas e bioclimatologia; coleta de dados, sobre a cidade de Florianópolis e suas características climáticas e territoriais; e elaboração da proposta conceitual.

A segunda etapa constou da elaboração da proposta arquitetônica, a qual apresentou o objetivo de atender, desde o início do processo projetual, às premissas estabelecidas e estratégias bioclimáticas apontadas para a cidade de Florianópolis - SC. A escolha e dimensionamento dos elementos de sombreamento e aberturas foram baseados nessas premissas. Ao final do processo, simulações computacionais foram utilizadas para indicar o desempenho da edificação e para indicar o nível de eficiência da edificação pelo Método Prescritivo do RTQ-C, este último com o programa Domus Eletrobras.

\section{RESULTADOS}

\subsection{Implantação e análise do terreno}

O terreno escolhido para a implantação da Biblioteca Parque de Santa Catarina corresponde a um recorte da área do Aterro da Baía Sul, de $18.627 \mathrm{~m}^{2}$. Este compreende o espaço em que coexistem partes do projeto paisagístico de Burle Marx para o Parque Metropolitano Francisco Dias Velho (1978) e edificações não previstas para ocupar o local, as quais o fazem de maneira desordenada e provisória (Figura 01).

A orientação da edificação foi condicionada pela posição das palmeiras imperiais do projeto de Burle Marx e também para que as principais fachadas fossem orientadas, mais a Norte-Sul possível, o que favorece a ventilação natural e o controle da insolação. A disposição dos ambientes, por sua vez, foi definida de acordo com a prévia 
setorização do volume e de acordo com as condições climáticas locais. Foram identificadas as necessidades de insolação e ventilação específicas para cada um deles.

Figura 1 - Aterro da Baía Sul e uso dos espaços

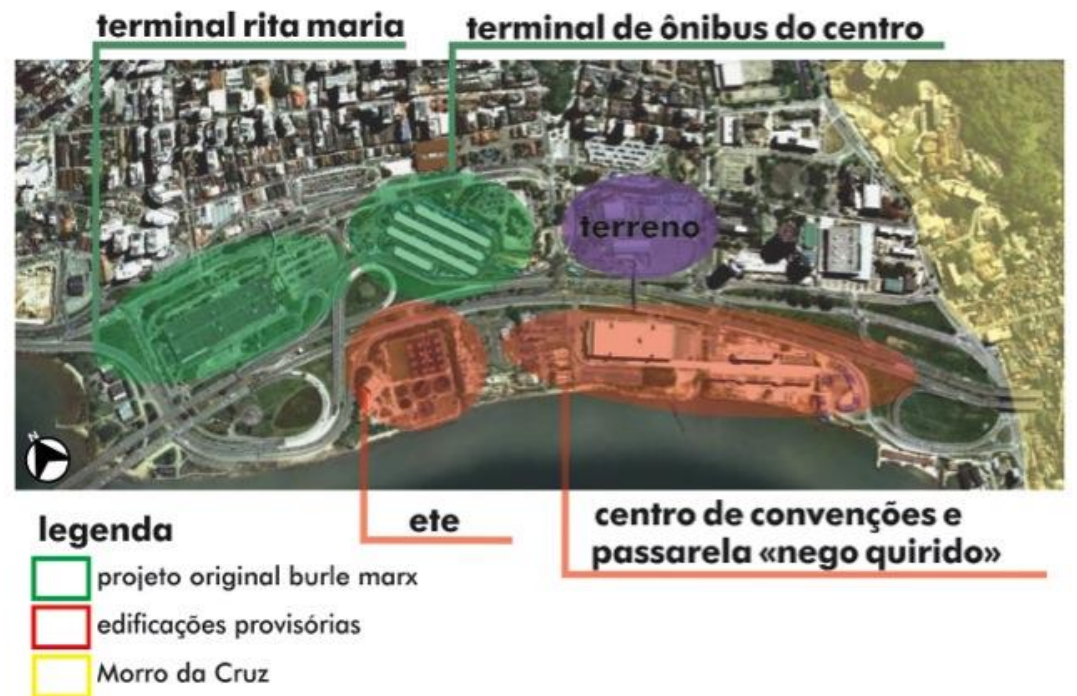

Fonte: Google Earth modificado pela autora (2013)

Entre os espaços externos destacam-se o Caminho Burle Marx e a Passarela, os quais serão mantidos de acordo com o projeto original para o Parque, e já existentes no local. O Jardim de Leitura, por sua vez, configura um espaço de transição entre os ambientes internos à edificação e os espaços do futuro Parque, e indica a ampliação dos limites para a convivência, leitura e integração entre os usuários. Os jardins densos, localizados na porção Sul do terreno, serão compostos por espécies de médio e grande porte, o qual funciona como barreira natural ao ruído da rodovia e ao vento sul, responsável por mudanças bruscas de temperatura (Figura 02).

\section{Figura 2 - Análise do terreno}

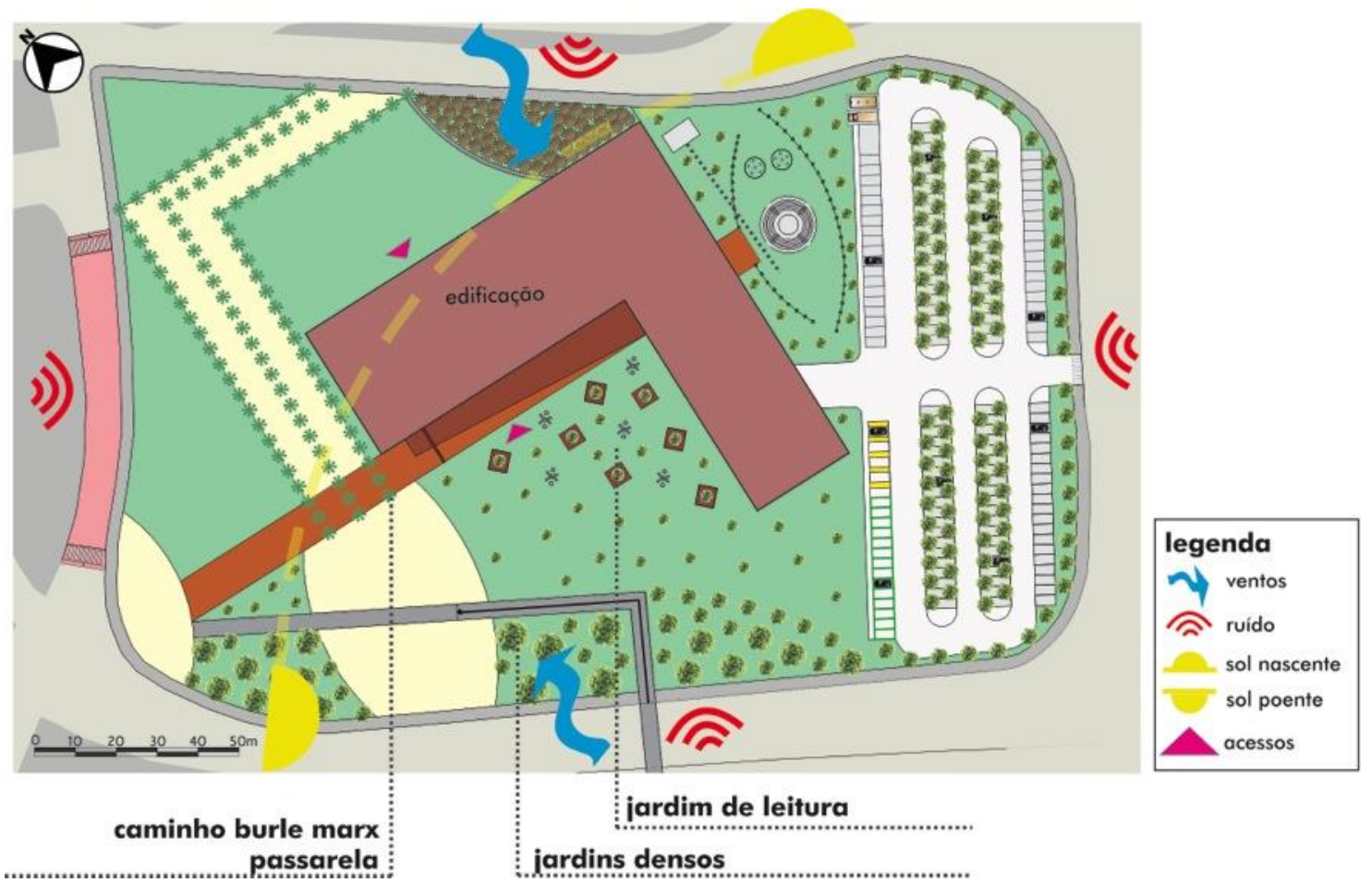




\subsection{Setorização da edificação}

O partido surgiu da necessidade da delimitação da área ocupada pelos ambientes externos de convivência, já que o terreno está inserido em um futuro parque urbano. Para isso, os dois volumes perpendiculares entre si delimitaram uma praça central de convivência. A configuração de 3 volumes diferentes, por sua vez, representa os 3 núcleos de uso nos quais a edificação foi dividida: Apoio (amarelo), o qual abrigará os ambientes de acesso restrito aos funcionários; Leitura (vermelho), com ambientes de convívio coletivo; e Acervo (verde), com planta livre e condições de armazenamento dos títulos (Figura 03).

Figura 3 - Setorização da edificação

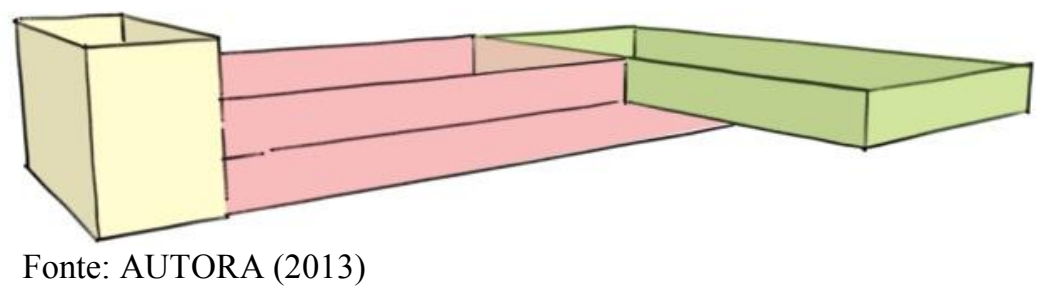

\subsection{Bloco "Acervo"}

A concepção arquitetônica do Bloco Acervo (SE - NO) (Figura 04) exigiu maior preocupação com as condições térmicas e de umidade internas. Por isso, para proporcionar o condicionamento passivo, foram adotadas estratégias bioclimáticas capazes de promover a ventilação cruzada. Foram projetados peitoris ventilados, com a possibilidade de fechamento, quando necessário, além da ventilação cruzada através das aberturas.

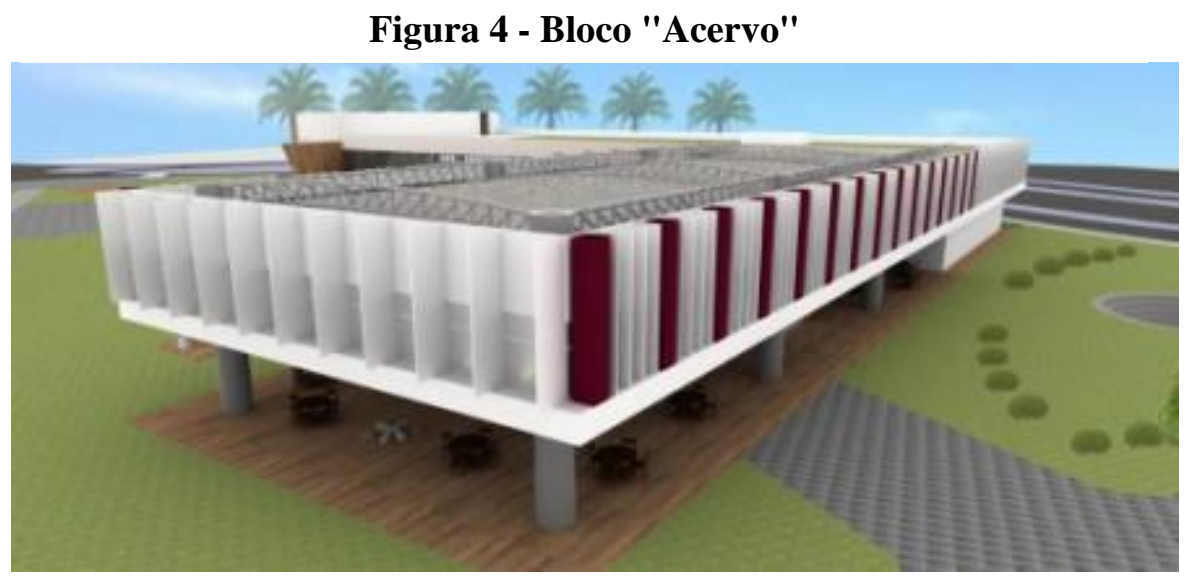

Fonte: AUTORA (2013)

As fachadas NO e SE, por sua vez, apresentam dutos de ar, de cor escura, que absorvem o calor do sol, de acordo com o horário do dia. A abertura para saída de ar encontra-se na parte superior do duto. No período da manhã, os dutos da fachada SE recebem radiação solar direta e se aquecem, contribuindo para a ventilação cruzada por diferença de temperatura. No período da tarde, por sua vez, ocorre o inverso: os dutos da fachada NO são aquecidos e proporcionam a ventilação cruzada. As combinações alternadas entre os sistemas de ventilação propostos também pode ser explorada, e esta fornece diferentes opções de controle de ventilação e renovação do ar para os usuários, no inverno e verão (Figura 05). 
Figura 5 - Opções de ventilação cruzada

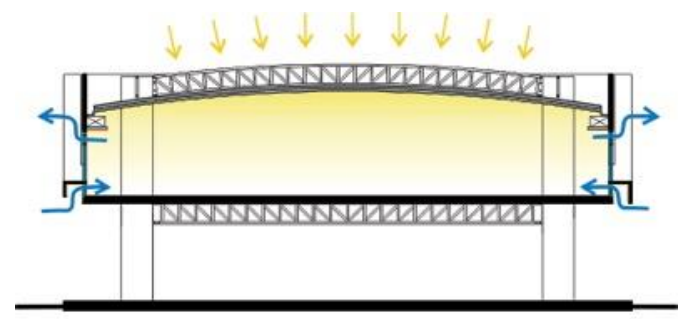

peitoril - peitoril/aberturas

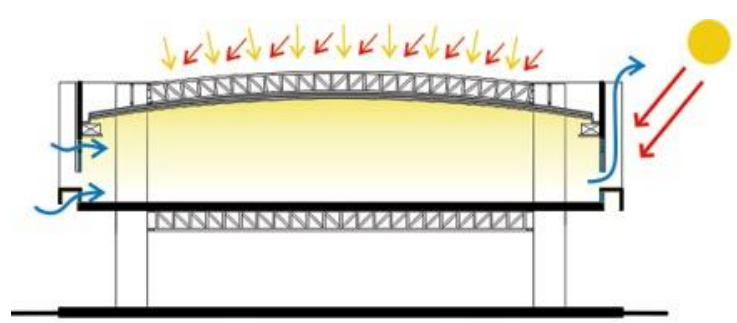

abertura - dutos/peitoril (manhã)

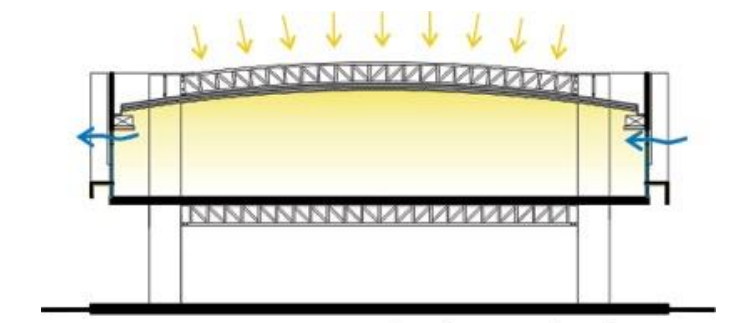

abertura - aberturas

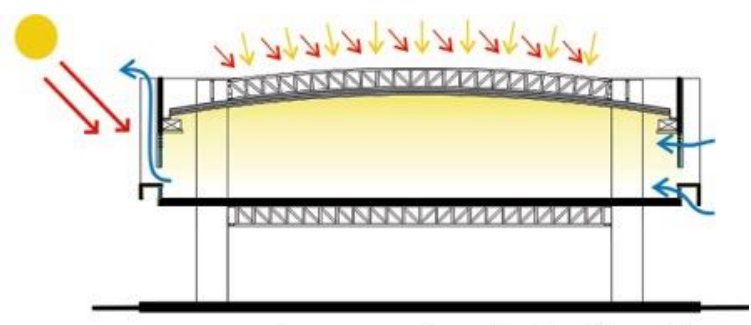

abertura - dutos/peitoril (tarde)

Fonte: AUTORA (2013)

Nas situações em que nenhuma das estratégias e combinações de ventilação natural for suficiente, os sistemas híbridos e ativos de condicionamento são acionados. Foram previstos, por sua vez, dois ambientes com condições especiais e controladas de condicionamento de ar e umidade durante todas as horas do ano, entre eles o que armazena as obras raras do acervo.

Entre os dutos de ventilação propostos foram incorporados brises verticais metálicos automatizados, de cor branca. No período da manhã, os brises da fachada NO permanecem abertos e, no período da tarde, tal situação ocorre com os brises da fachada SE. A adoção dos brises abertos no período de sombreamento das fachadas proporciona permeabilidade visual entre ambientes externos $\mathrm{e}$ internos da biblioteca $\mathrm{e}$ aproveitamento da luz natural.

Para o controle da umidade relativa do ar, a qual é elevada em Florianópolis para o condicionamento de livros, foi proposto o revestimento em sílica na entrada dos dutos de ventilação e do peitoril ventilado. Tal material é absorvedor de umidade e a manutenção e reposição necessárias são mínimas. Nas situações em que monitoradas oscilações de umidade prejudiciais ao acervo, o sistemas híbridos e ativos de condicionamento de ar também são acionados.

\subsection{Cobertura do Bloco "Acervo": Aproveitamento da luz natural}

Os níveis de iluminância desse bloco devem ser compatíveis com a atividade desempenhada e a iluminação deve ser homogênea em todo o ambiente. Portanto, foi desenvolvida uma malha zenital (Figura 06), composta por módulos de alumínio $(25 \mathrm{~cm} \times 22 \mathrm{~cm} \times 15 \mathrm{~cm})$ dimensionados para bloquear a radiação solar direta dentro do ambiente, e, ao mesmo tempo, promover a reflexão da luz de forma homogênea (Figura 07). A utilização da iluminação natural proporciona economia do consumo de energia do edifício, já que, a iluminação artificial só será necessária nas horas em que os níveis de iluminância provenientes da luz natural difusa forem inferiores a 500 lux. 
Figura 6 - Malha Zenital

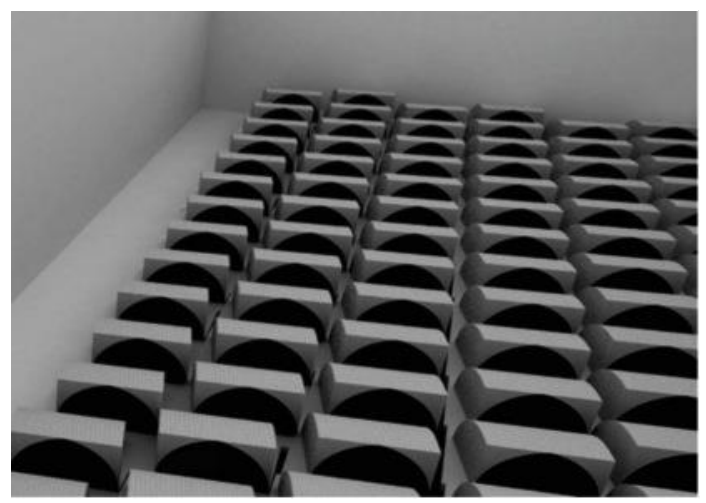

Fonte: AUTORA (2013)
Figura 7 - Estudo de sombreamento dos módulos (orientação S) - 22/12

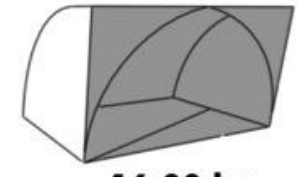

16:00 hs

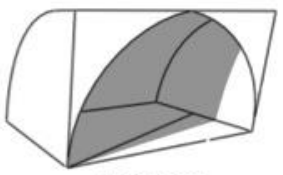

18:00 hs

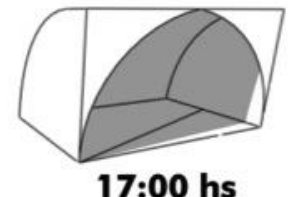

17:00 hs

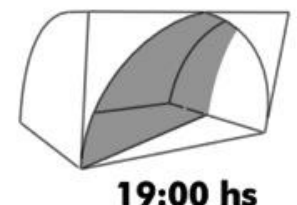

Fonte: AUTORA (2013)

\subsection{Blocos "Leitura" e "Apoio"}

As principais estratégias bioclimáticas aplicadas ao bloco orientado a NE - SO estão relacionadas com o conforto térmico e visual dos usuários, primordiais em ambientes de permanência prolongada. A ventilação cruzada por diferença de temperatura é proporcionada pelas grandes aberturas nas fachadas e facilitada pelo layout em planta livre dos ambientes, aproveitando-se da maior frequência e velocidade dos ventos na direção NE. O fenômeno do efeito chaminé ocorre devido à abertura vertical na parede externa do mezanino. A planta livre nesse bloco é um agente facilitador da ventilação natural.

Em relação à iluminação natural foram adotadas prateleiras de luz na fachada NO, para que a penetração da iluminação alcance maior profundidade no ambiente. As varandas, por sua vez, além de protegerem as fachadas da radiação solar direta, o que contribui para a diminuição do ofuscamento e dos ganhos térmicos, promovem espaços sombreados de permanência e convívio dos usuários.

Para o bloco que abriga áreas administrativas e depósitos foram propostos brises verticais de madeira certificada automatizados na fachada NO. Estes permanecem a $90^{\circ} \mathrm{com}$ a fachada no período da manhã (Figura 08) e fechados no período da tarde (Figura 09), para bloqueio da radiação solar direta. O ângulo de abertura destes brises permite a entrada de radiação solar no inverno e, se desejado pelo usuário da área administrativa, ele pode controlar a automação.

Figuras 8 e 9 - Vista da fachada NO (período da manhã e período da tarde)
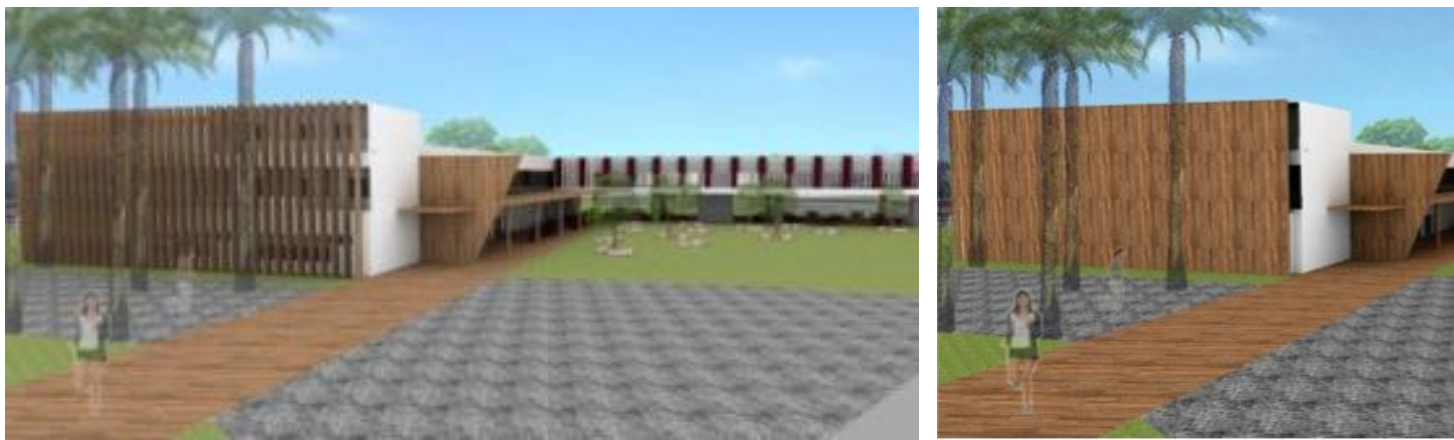

Fonte: AUTORA (2013) 


\subsection{Avaliação pelo Método Prescritivo do RTQ-C}

As estratégias bioclimáticas aplicadas desde o início do processo projetual foram pautadas e avaliadas de acordo com a literatura consultada. Para a validação destas estratégias aplicadas ao edifício, de acordo com os parâmetros utilizados no Brasil, este foi modelado no programa DOMUS - PROCEL EDIFICA e a etiqueta do RTQ-C foi emitida, utilizando o Método Prescritivo. Tal etiqueta, parcial para envoltória e iluminação, apresentou nível A de eficiência energética. Como bonificações para o método prescritivo foram considerados: $20 \%$ de economia com sistemas e equipamentos que racionalizem o uso de água, o que proporcionou 0,5 pontos, e $20 \%$ de economia com sistemas que aumentam comprovadamente a eficiência energética da edificação, tais como uso de painéis fotovoltaicos e sistema de inovação para aproveitamento de luz natural, que proporcionaram 0,5 pontos. Como o programa não simula a luz natural, a chaminé térmica (dutos de ventilação) e o desempenho da sílica, o método de simulação não foi adotado para esta análise. Outras ferramentas de avaliação podem ser aplicadas na análise e validação das estratégias bioclimáticas, entre elas a modelagem em programas de simulação computacional de desempenho térmico, como o EnergyPlus e luminoso, como o Daysim.

\section{CONSIDERAÇÕES FINAIS}

Durante o processo projetual da Biblioteca Parque de Santa Catarina, na região central de Florianópolis - SC buscou-se aplicar os conceitos teóricos sobre as Bibliotecas Parque, além das estratégias bioclimáticas adequadas às condições locais. A proposta da Biblioteca é que esta seja um espaço público de lazer, integrando os ambientes internos de leitura aos ambientes externos pertencentes a um parque público, e promovendo a inclusão social dos moradores da cidade, através da educação e da cultura. O projeto visa atender aos requisitos de conforto térmico e luminoso/visual para os usuários, associados às condições ideais de armazenamento do acervo. Este apresenta elementos arquitetônicos, como os dutos de ventilação e dispositivos de proteção solar, para proporcionar o condicionamento passivo e aproveitamento da iluminação natural. Em relação à iluminação natural, por sua vez, nos ambientes de leitura, as aberturas sombreadas e prateleiras de luz proporcionaram o seu aproveitamento. No bloco Acervo, a preocupação com o armazenamento das obras indicou o desenvolvimento de uma malha zenital, para o bloqueio da radiação solar direta dentro do ambiente, e, ao mesmo tempo, para proporcionar a reflexão da luz difusa.

Percebe-se, portanto, que a aplicação de estratégias bioclimáticas, desde o início do processo projetual, pode indicar a adequação do partido a condições climáticas locais, fato que contribui para a economia de energia de operação. A experiência demonstra que as decisões tomadas ao longo da elaboração do projeto podem atender às necessidades específicas de tipologias complexas, como a de bibliotecas, e, ao mesmo tempo, proporcionar conforto ambiental aos usuários e adequação aos conceitos simbólicos e sociais desejados.

\section{REFERÊNCIAS}

ASSOCIAÇÃO BRASILEIRA DE NORMAS TÉCNICAS. NBR 15220-3 - Desempenho térmico de edificações: Parte 3 - Zoneamento bioclimático brasileiro e diretrizes construtivas para habitações unifamiliares de interesse social. Rio de Janeiro, 2005.

BABBIE, E. The practice of social research. 4 Ed. Belmont: Wadsworth Publ., 1986. 
CIDEU [internet]. Parques Bibliotecas Medellín. Disponível em: < http://www.cideu.org/index.php?mod=objeto\&act=verObjeto\&idObjeto=217> . Acesso em: $15 / 12 / 13$

GOULART, S. Dados climáticos para avaliação de desempenho térmico de edificações em Florianópolis [dissertação]. Florianópolis: Universidade Federal de Santa Catarina, Departamento de Engenharia Civil, Florianópolis, 1993.

IBGE [internet]. Dados dos municípios. 2010. Disponível em: $<$ http://www.ibge.gov.br/home/>. Acesso em 20/12/13.

IFLA. Manifesto da UNESCO sobre Bibliotecas Públicas. UNESCO, 1994. Disponível em: $<$ http://archive.ifla.org/VII/s8/unesco/port.htm $>$. Acesso em 15/12/13.

MARTINS, L.C. Repensando o aterro da Baía Sul [trabalho de conclusão de curso]. Florianópolis: Universidade Federal de Santa Catarina, Curso de Arquitetura e Urbanismo, 2012.

OGDEN, S. Meio ambiente. Tradução Elizabeth Larkin Nascimento, Francisco de Castro Azevedo. 2ed. Rio de Janeiro: Projeto Conservação Preventiva em Bibliotecas e Arquivos: Arquivo Nacional, 2001.

SANTOS, Paulo César dos. Espaço e memória - O Aterro da Baía Sul e o desencontro marítimo de Florianópolis [dissertação]. Florianópolis: Universidade Federal de Santa Catarina, Departamento de História, Florianópolis, 1997.

TRINKLEY, M. Considerações sobre preservação na construção e reforma de bibliotecas: planejamento para preservação. Tradução: Luiz Antonio Macedo Ewbank. 2ed. Rio de Janeiro: Projeto Conservação Preventiva em Bibliotecas e Arquivos: Arquivo Nacional, 2001.

VALADÃO, J.B. Avaliação do conforto térmico de uma biblioteca universitária pela ASHRAE Standard 55 e EN 15251 [dissertação]. Departamento de Engenharia Civil. Viçosa: Universidade Federal de Viçosa, 2011. 